\title{
SACROILIITIS AS THE FIRST MANIFESTATION OF DISSEMINATED TUBERCULOSIS IN PATIENT WITH MYASTHENIA GRAVIS: CASE REPORT
}

Marco Felipe Macedo Alves ${ }^{1}$, Carlos Eduardo Lopes Tavares de Melo ${ }^{1}$, Clarice Alves Esmeraldo ${ }^{1}$, Henrique de Ataíde Mariz ${ }^{1}$, Claudia Diniz Lopes Marques ${ }^{1}$, Rafaela Silva Guimarães Gonçalves ${ }^{1, \star}$, Angela Luzia Branco Pinto Duarte ${ }^{1}$

1.Universidade Federal de Pernambuco, Recife (PE), Brazil.

*Corresponding author: rafa_sgg@hotmail.com

\section{BACKGROUND}

Bone and/or joint involvement is an uncommon extrapulmonary manifestation of Mycobacterium tuberculosis infection, whose diagnosis can be difficult and can lead to significant morbidity and mortality. Tuberculous sacroiliitis is a rare manifestation of osteoarticular tuberculosis and should be included in the differential diagnosis of inflammatory low back pain.

\section{CASE REPORT}

A 41-year-old woman from Recife, diagnosed with myasthenia gravis and chronically using azathioprine $3 \mathrm{mg} / \mathrm{kg} / \mathrm{day}$ and prednisone $20 \mathrm{mg} /$ day. She was referred for evaluation due to inflammatory rhythm pain in the left gluteus for six months, with subsequent onset of daily evening fever, night sweats and dry cough for two months, and evolving with mental confusion one week before admission. On physical examination, a positive FABER maneuver was noted in the left sacroiliac joint. She had already performed a sacroiliac magnetic resonance imaging (MRI) showing left sacroilitis with blurring of soft tissues (Figure 1). Chest computed tomography (CT) was performed showing findings suggestive of miliary tuberculosis (Figure 2) and skull MRI showed a nodular image in the right basal ganglia, suggestive of tuberculoma given the clinical presentation (Figure 3). Based on the epidemiology, clinical signs and symptoms, imaging, and severity of the condition, a diagnosis of disseminated tuberculosis (miliary pulmonary, osteoarticular and central nervous system) was made, and tuberculostatic therapy was started, with defervescence occurring on the third day of treatment and improvement of pain around the seventh day. She remains in outpatient follow-up, maintaining good clinical response to the instituted therapy, which is expected to end after 12 months treatment.

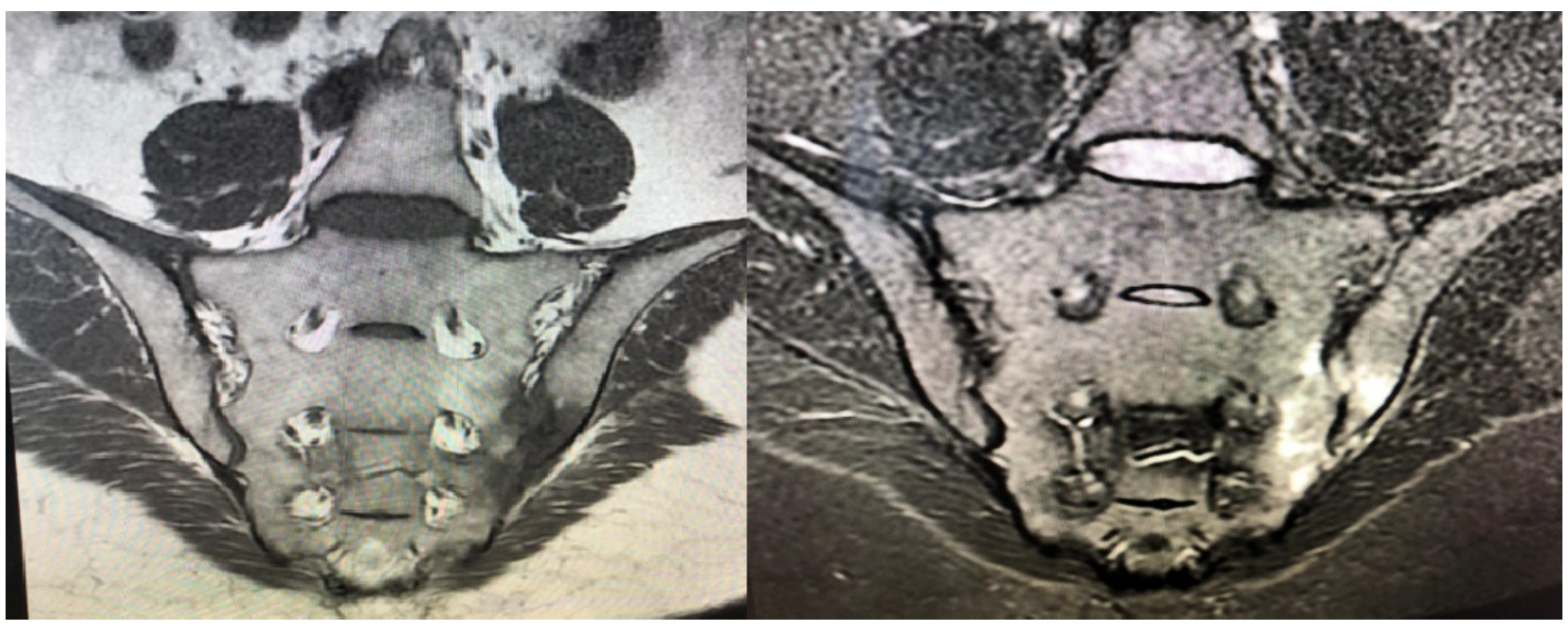

Figure 1. Coronal T1-weighted (left) and STIR-weighted (right) MRI showing left sacroiliitis with bone erosions and periarticular soft tissue blurring, compatible with tuberculous sacroiliitis.

Realização: 


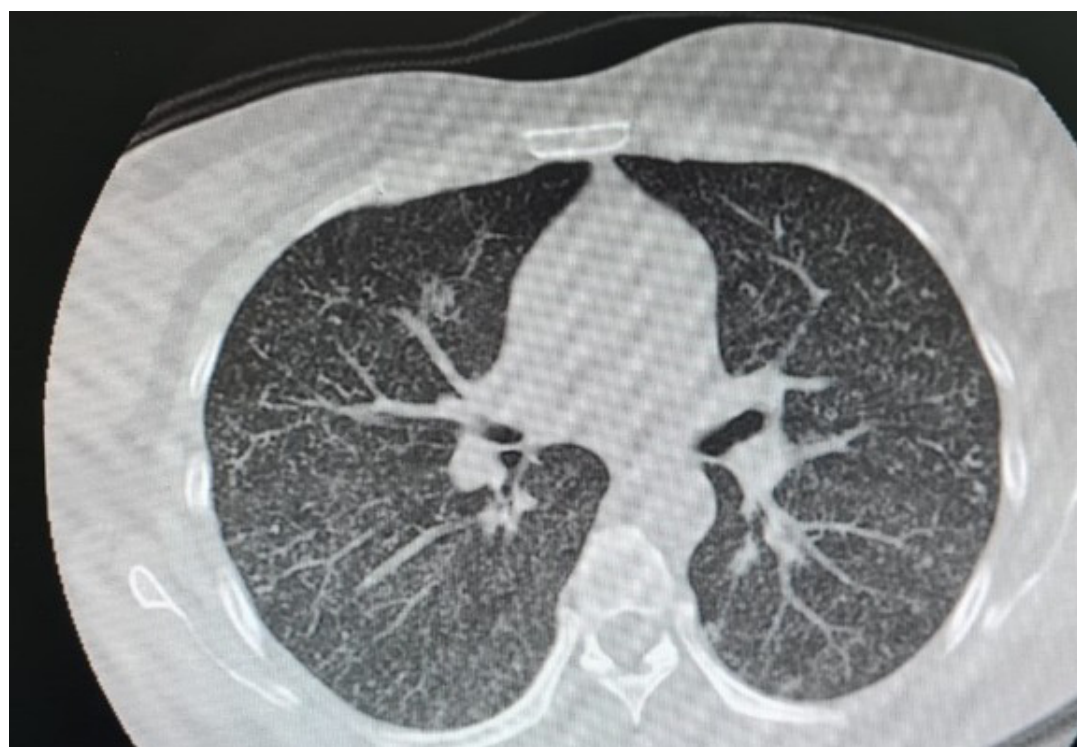

Figure 2. Axial chest CT showing small uniform nodules, uniformly distributed in both lungs, suggestive of miliary tuberculosis.

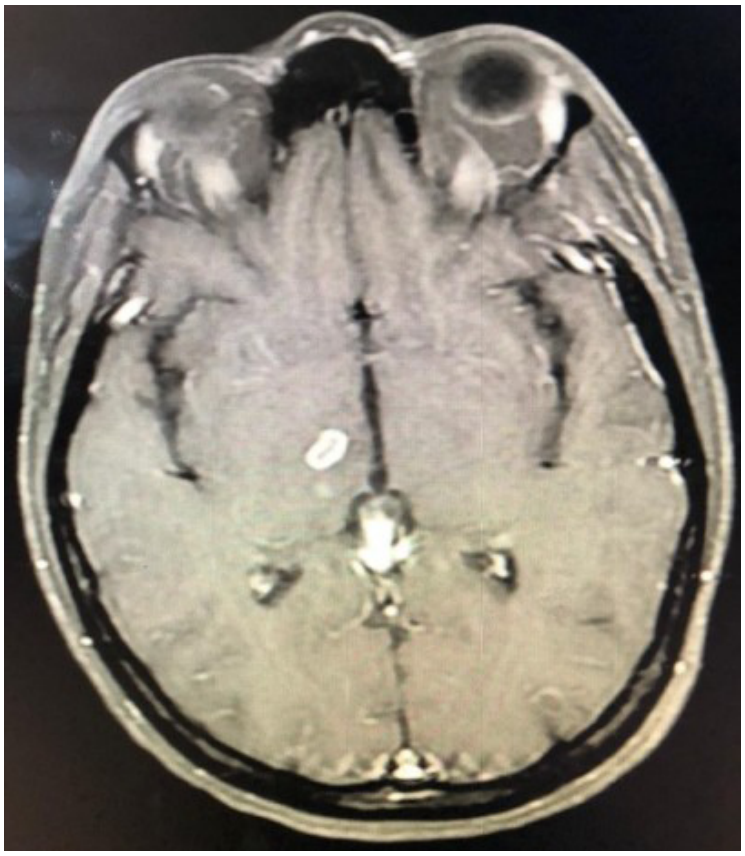

Figure 3. Axial T1-weighted skull MRI showing ring-enhancement nodular area in right basal ganglia, which, in our case, suggests tuberculoma.

\section{CONCLUSION}

We report a case of tuberculous sacroilitis in an adult patient using immunosuppression, living in an endemic region, with musculoskeletal complaints preceding the manifestations of disseminated tuberculosis.

\section{KEYWORDS}

Osteoarticular tuberculosis, Miliary tuberculosis, Central nervous system tuberculosis, Myasthenia gravis. 